\title{
Acceptance of telemedicine by kidney transplant recipients during the COVID-19 pandemic: A survey study of patient experiences
}

\author{
Joshua Wolf $^{*}$, Jacob Rubin ${ }^{2}$, Andrea Bossie ${ }^{1}$ and Jose Lizcano ${ }^{1}$ \\ ${ }^{1}$ Piedmont Transplant Institute, Atlanta, GA, USA \\ ${ }^{2}$ University of Florida, Gainesville, FL, USA
}

\begin{abstract}
COVID-19 has motivated unprecedented changes to telemedicine including kidney transplant patient care. Telemedicine with this population is not well described.

We assessed the comfort and experience of post-kidney transplant patients with telemedicine versus an in-person visit using a 16-question survey between March and June 2020. Patients completed the survey via email or telephone. Participants graded their experience using a 5-point assessment (1=most positive; $5=1$ east desirable).

197 out of 381 telemedicine patients responded. Survey questions were consolidated into 7 groups. Living (1.38) vs deceased donor (1.56, P=0.018) recipients, less than 6 months post-transplant (1.33) vs 1.52 for 6-12 months, 1.56 for $>12$ months, $\mathrm{P}=0.033$ ); non-African Americans (AA) (1.36) vs AA (1.60, $\mathrm{P}=0.002)$ responded more favorably to ease of scheduling and entering the portal. Non-AA (1.26) vs AA (1.40, $\mathrm{P}=0.034)$ rated patient/provider interaction higher. Patients age 50 or less (1.33), 65 and over (1.49) found better quality of the Internet connection with a provider than 51-64 (1.73, P=0.005). Patients < 50 (1.35) and women (1.39) found telemedicine simpler to use than 51-64 (1.66) and over $65(1.58, \mathrm{P}=0.045)$ and men $(1.62, \mathrm{P}=0.035)$, respectively. Patients who lived greater versus less than 50 miles from our center: telemedicine is the same as in person visit (1.99 vs $2.38, \mathrm{P}=0.009)$; an acceptable alternative $(1.43$ vs 1.74 , $\mathrm{P}=0.009)$; enjoyed their experience and comfort substituting telemedicine for an in-person provider in the future $(2.10 \mathrm{vs} 1.76, \mathrm{P}=0.03)$.
\end{abstract}

Post-kidney transplant patients responded favorably to telemedicine. Some patient demographics influenced survey responses. These results suggest telemedicine can substitute for an in-person visit.

\section{Introduction}

Telemedicine has been used for decades in clinical settings [1-2]. Probably one of the earliest and most famous uses of hospital-based telemedicine was in the late 1950s and early 1960s when a closedcircuit television link was established between the Nebraska Psychiatric Institute and Norfolk State Hospital for psychiatric consultations $[1,3]$. The Health Resources and Services Administration (HRSA) of the US department of Health and Human Services (HHS) establishes Telemedicine as a tool to allow healthcare providers to evaluate, diagnose and treat patients without the need for an in-person visit [4]. On March 11, 2020, the World Health Organization declared the COVID-19 outbreak a pandemic [5]. Telemedicine is making a very positive contribution to healthcare during this pandemic and is being used in a variety of ways [6]. Telemedicine is bridging the gap between people, physicians and health systems, enabling virtually everyone to stay at home and communicate with physicians via virtual channels [6].

Changes in the way that health care is delivered during this pandemic were needed to reduce staff exposure to ill persons, preserve personal protective equipment, and minimize the impact of patient surges on facilities $[7,8]$. Telemedicine services help provide necessary care to patients while minimizing the transmission risk of SARS-CoV-2, the virus that causes COVID-19, to healthcare personnel and patients [7]. Also, as Telemedicine becomes more accessible, this technology has the potential to reduce language barriers between patients and providers, making it easier to care for those who need translation and giving them information that they can more clearly understand [9]. Telemedicine has emerged dramatically during the COVID-19 pandemic and allowed clinicians to offer the standard of care to their patients with COVID-19, but with heightened public health consciousness [10].

Specifically, for kidney transplant recipients, telemedicine can reduce the cost and time of travel as well as improve work productivity and savings for both recipients and caregivers, while minimizing exposure to COVID-19 [10,11]. In a recently published study, the kidney transplant program at Columbia University initially found that implementation of telemedicine was feasible and effective for routine and for-cause visits in the care of transplant recipients during the COVID-19 [12].

Piedmont Transplant Institute (PTI) has performed kidney transplants for over 30 years and continues to manage thousands of postkidney transplant patients. These patients are all immunosuppressed, some of them have other comorbidities such as obesity, diabetes, hypertension or chronic lung disease are at elevated risk for infection,

*Correspondence to: Joshua Wolf, MD, 1968 Peachtree Road, NW, Building 77, 6th floor Atlanta, GA 30309, USA, E-mail: Joshua.wolf@piedmont.org

Key words: telemedicine, kidney transplantation, survey, outcomes

Received: March 06, 2021; Accepted: March 15, 2021; Published: March 18, 2021 
making them an especially vulnerable population during the COVID-19 pandemic [13-15]. In March, 2020, our Transplant Institute increased utilization of telemedicine with kidney transplant recipients in an effort to serve our kidney transplant community. This virtual channel allows these patients to continue to cover their special health needs while limiting their exposure to a potentially lethal virus.

To better understand patients' satisfaction with telemedicine we sent a questionnaire to our recipients after their Telemedicine visit. This questionnaire assessed patients' ability to schedule and enter the Telemedicine portal, quality of care during the Telemedicine visit, amount and quality of time spent with provider, and their assessment of Telemedicine versus an in-person visit.

\section{Materials and Methods}

We conducted a single-center, retrospective study to assess the comfort and experience of post-kidney transplant patients with telemedicine between March and June 2020, at Piedmont Transplant Institute in Atlanta, Georgia. The Piedmont Hospital Institutional Review Board approved the study (PHIRB policy \#6421 and \#6422). Our center used both Doxy.me and Doximity video chat, which were both HIPAA compliant platforms. Only patients transplanted at our institute and who used Telemedicine were included in this analysis. Participants were at least age 18 and English speaking.

The recipients' post-transplant coordinators contacted them by phone to confirm they had Internet access and a smart phone or computer. Participants were then emailed a link to connect them to the telemedicine visit application. The day prior to their appointment a staff member called the patient to have them complete a Needs Assessment and Medication Reconciliation, which was entered into the medical record (Epic) in preparation for their visit. At the end of the visit, the provider informed the participant of the satisfaction survey. Patients then had the option of receiving the survey by email to complete and email back. The kidney transplant provider who evaluated the patient documented the participants' visual and verbal consent in the electronic medical record. Participants did not receive compensation for their participation. Four transplant nephrologists and two nurse practitioners with physician supervision performed visits during the study period. Privacy was protected using a numbering system for the patient identifier. Providers had access to the patient's electronic medical record during the Telemedicine visit. The patient was given the option to accept or deny completing the questionnaire. There was no foreseeable risk to the participants and no specimens were collected during this study. The patients were emailed a 16 -question survey (Appendix). If they did not respond after two emails then we attempted to contact them and complete the survey over the phone.

Participants answered a 16-question survey, which was designed to evaluate the ease of scheduling and entering the video conferencing portal; patient provider interaction; quality of the internet connection with the provider; comparison of the telemedicine visit to an inperson visit; simplicity of using telemedicine; level of comfort with telemedicine; acceptance of a virtual versus an in-person visit for their post-transplant care. Participants graded their experience using a 5 -point assessment with 1 being the most positive and 5 being least desirable.

\section{Results}

During the 4-month study period from March 2020 through June 2020, 197 out of 381 (51.7\%) post-kidney transplant recipients seen through Telemedicine responded via email or telephone. We evaluated these responses based on the following demographics which were obtained through the patient's medical records: age, time from transplant, donor type, gender, race, and number of miles from our transplant center (Distance). These demographics are shown in Table 1. RedCap software managed survey data for statistical analysis, which was performed using one-way ANOVA. Analysis involving 3 groups was followed by Tukey pairwise comparisons.

Our survey results are summarized in Table 2, which displays the average results from each question group using the 5-point assessment broken down by demographic, standard deviation, and P-value. Ease of scheduling an appointment and entering the videoconference portal, was significantly associated with time from transplant (0-6 months 1.33 , 6-12 months 1.52 , > 12 months $1.56, \mathrm{P}=0.03$ ), donor type (deceased 1.56 vs living $1.38, \mathrm{P}=0.02$ ), and race (Non-AA 1.36 vs AA $1.60, \mathrm{P}=$ 0.02 ), but not with age, gender, or distance from transplant center.

Patient provider interaction using Telemedicine questions were defined by rating the care from the provider, how well the provider answered questions, provider's ability to explain the follow-up care, provider listening to patient's needs, the amount of time provider spent with the patient, and how easily the patient could communicate with the provider using the Telemedicine system. The only statistically significant difference was between African Americans (AA) (1.60) and non-AA $(1.36, \mathrm{P}=0.002)$.

The quality of the internet connection with the provider was measured by asking if the patient could easily hear the provider using telemedicine and if the patient could see the provider as well as if they were meeting in person. Patients between the ages of 51-64 (1.73) were significantly less satisfied than other age groups (50 or less 1.33 and 65 and older 1.49, $\mathrm{P}=0.005)$. All other demographics showed no statistically significant differences.

Patients 50 and under (1.35) more strongly agreed that telemedicine was simple to use versus ages 51-64 (1.66) and ages 65 and older (1.58, $\mathrm{P}$ $=0.045)$. This also applied to women (1.39) versus men $(1.62, \mathrm{P}=0.03)$.

Patients who lived more than 50 miles from our center felt telemedicine is the same or as good as an in-person visit (1.99 vs 2.38 , $\mathrm{P}=0.009$ ), an acceptable alternative to provide the proper care for their

Table 1. Patient Demographics

\begin{tabular}{|l|c|}
\hline Patient Characteristics & Number \\
\hline Age & 72 \\
\hline 50 and Under & 61 \\
\hline $51-64$ & 64 \\
\hline 65 and Older & \\
\hline Time from Transplant (months) & 59 \\
\hline $0-6$ & 41 \\
\hline $6-12$ & 97 \\
\hline$>12$ & \\
\hline Donor Type & 112 \\
\hline Deceased & 85 \\
\hline Living & \\
\hline Gender & 89 \\
\hline Female & 108 \\
\hline Male & \\
\hline Race & 98 \\
\hline African American & 99 \\
\hline non-African American & \\
\hline Distance (miles) & 121 \\
\hline$\leq 50$ & 76 \\
\hline Over 50 & \\
\hline
\end{tabular}


Table 2. Survey results using the 5-point assessment, which 1 being most positive and 5 being least desirable stratified by patient demographic. Standard deviation is listed in parenthesis after each 5-point assessment result

\begin{tabular}{|c|c|c|c|c|c|c|c|c|}
\hline & & $\begin{array}{c}\text { Scheduling and } \\
\text { entering the video } \\
\text { conferencing portal }\end{array}$ & $\begin{array}{l}\text { Patient/provider } \\
\text { interaction using } \\
\text { Telemedicine }\end{array}$ & $\begin{array}{c}\text { Quality of internet } \\
\text { connection with } \\
\text { provider }\end{array}$ & $\begin{array}{l}\text { I think that the visit } \\
\text { using Telemedicine } \\
\text { is the same }\end{array}$ & $\begin{array}{c}\text { I felt that this } \\
\text { Telemedicine visit } \\
\text { was an acceptable } \\
\text { alternative }\end{array}$ & $\begin{array}{l}\text { Telemedicine was } \\
\text { simple to use }\end{array}$ & $\begin{array}{c}\text { I enjoyed my patient } \\
\text { experience using } \\
\text { Telemedicine }\end{array}$ \\
\hline Age $(y$ & $\begin{array}{l}\text { ars) } \\
\begin{array}{l}\leq 50 \\
51-64 \\
65+ \\
\text { p-value }\end{array}\end{array}$ & $\begin{array}{c}1.4(0.48) \\
1.56(0.61) \\
1.48(0.53) \\
0.37\end{array}$ & $\begin{array}{c}1.29(0.40) \\
1.39(0.53) \\
1.33(0.38) \\
0.45\end{array}$ & $\begin{array}{c}1.33(0.55) \\
1.73(0.93) \\
1.49(0.58) \\
\mathbf{0 . 0 0 5}\end{array}$ & $\begin{array}{c}2.10(1.0) \\
2.34(0.95) \\
2.25(1.1) \\
0.38\end{array}$ & $\begin{array}{c}1.64(0.86) \\
1.70(0.88) \\
1.53(0.67) \\
0.48\end{array}$ & $\begin{array}{c}1.35(0.61) \\
1.66(0.87) \\
1.58(0.75) \\
\mathbf{0 . 0 4 5}\end{array}$ & $\begin{array}{c}1.92(1.0) \\
2.10(1.0) \\
1.91(1.1) \\
0.50\end{array}$ \\
\hline $\begin{array}{l}\text { Time fi } \\
\text { (month }\end{array}$ & 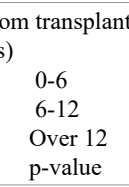 & $\begin{array}{c}1.33(0.42) \\
1.52(0.49) \\
1.56(0.60) \\
\mathbf{0 . 0 3}\end{array}$ & $\begin{array}{c}1.30(0.38) \\
1.35(0.36) \\
1.35(0.49) \\
0.78\end{array}$ & $\begin{array}{c}1.35(0.55) \\
1.64(0.68) \\
1.54(0.80) \\
0.10\end{array}$ & $\begin{array}{c}2.05(1.0) \\
2.32(0.99) \\
2.29(1.0) \\
0.30\end{array}$ & $\begin{array}{c}1.54(0.65) \\
1.59(0.74) \\
1.69(0.92) \\
0.51\end{array}$ & $\begin{array}{c}1.37(0.67) \\
1.54(0.67) \\
1.60(0.82) \\
0.19\end{array}$ & $\begin{array}{c}1.71(0.85) \\
2.07(1.1) \\
2.08(1.1) \\
0.07\end{array}$ \\
\hline Donor & $\begin{array}{l}\text { Deceased } \\
\text { Living } \\
\text { p-value }\end{array}$ & $\begin{array}{c}1.56(0.56) \\
1.38(0.49) \\
\mathbf{0 . 0 2}\end{array}$ & $\begin{array}{c}1.36(0.47) \\
1.31(0.38) \\
0.41\end{array}$ & $\begin{array}{c}1.45(0.59) \\
1.58(0.85) \\
0.20\end{array}$ & $\begin{array}{c}2.26(1.0) \\
2.18(1.0) \\
0.57\end{array}$ & $\begin{array}{c}1.63(0.82) \\
1.61(0.80) \\
0.85\end{array}$ & $\begin{array}{c}1.54(0.70) \\
1.49(0.83) \\
0.70\end{array}$ & $\begin{array}{c}2.04(1.1) \\
1.88(0.93) \\
0.30\end{array}$ \\
\hline Sex & $\begin{array}{l}\text { Female } \\
\text { Male } \\
\text { p-value }\end{array}$ & $\begin{array}{c}1.45(0.48) \\
1.52(0.58) \\
0.37\end{array}$ & $\begin{array}{c}1.27(0.37) \\
1.39(0.48) \\
0.06\end{array}$ & $\begin{array}{c}1.41(0.59) \\
1.59(0.79) \\
0.08\end{array}$ & $\begin{array}{c}2.08(0.99) \\
2.35(1.0) \\
0.07\end{array}$ & $\begin{array}{c}1.53(0.78) \\
1.70(0.82) \\
0.13\end{array}$ & $\begin{array}{c}1.39(.65) \\
1.62(.82) \\
\mathbf{0 . 0 3}\end{array}$ & $\begin{array}{c}1.90(1.0) \\
2.03(1.1) \\
0.038\end{array}$ \\
\hline Race & $\begin{array}{l}\text { Non- A.A. } \\
\text { A.A. } \\
\text { p-value }\end{array}$ & $\begin{array}{c}1.36(.49) \\
1.60(.55) \\
\mathbf{0 . 0 0 2}\end{array}$ & $\begin{array}{c}1.26(.40) \\
1.40(.46) \\
\mathbf{0 . 0 3}\end{array}$ & $\begin{array}{c}1.44(0.73) \\
1.55(0.68) \\
0.29\end{array}$ & $\begin{array}{c}2.14(1.0) \\
2.30(1.0) \\
0.30\end{array}$ & $\begin{array}{c}1.58(0.76) \\
1.67(0.87) \\
0.47\end{array}$ & $\begin{array}{c}1.46(0.77) \\
1.57(0.73) \\
0.34\end{array}$ & $\begin{array}{c}1.87(0.99) \\
2.06(1.1) \\
0.20\end{array}$ \\
\hline Distanc & $\begin{array}{l}\text { (miles) } \\
\leq 50 \\
\text { Over } 50 \\
\text { p-value }\end{array}$ & $\begin{array}{c}1.48(0.52) \\
1.50(0.57) \\
0.81\end{array}$ & $\begin{array}{c}1.36(0.43) \\
1.30(0.45) \\
0.37\end{array}$ & $\begin{array}{c}1.50(0.68) \\
1.51(0.77) \\
0.96\end{array}$ & $\begin{array}{c}2.38(1.1) \\
1.99(0.93) \\
\mathbf{0 . 0 0 9}\end{array}$ & $\begin{array}{c}1.74(0.86) \\
1.43(0.68) \\
\mathbf{0 . 0 0 9}\end{array}$ & $\begin{array}{c}1.50(0.72) \\
1.55(0.81) \\
0.61\end{array}$ & $\begin{array}{c}2.10(1.1) \\
1.76(0.89) \\
\mathbf{0 . 0 3}\end{array}$ \\
\hline
\end{tabular}

transplant (1.43 vs $1.74, \mathrm{P}=0.009)$, and enjoyed their patient experience and comfort substituting telemedicine for an in-person provider in the future ( $2.10 \mathrm{vs} 1.76, \mathrm{P}=0.03)$. There was no statistically significant difference seen across all other demographics in these three question groups.

During the study period, this cohort had no rejection episodes or graft loss.

\section{Discussion}

We present a survey evaluating the acceptance of using telemedicine as an alternative to a post-kidney transplant provider visit during the COVID-19 pandemic. Our study found that patients are overall satisfied using Telemedicine as an acceptable alternative for a faceto-face visit after kidney transplant. These patients felt that the care provided with telemedicine was adequate, simple to use, convenient as they didn't have to travel, and they had enough time with their provider to address all questions and concerns. Our response rate of $51.7 \%$ was significantly higher than observed in other survey studies related to telehealth [16-18]. Some patient demographics influenced survey responses. We believe that this is one of the first studies to evaluate post-kidney transplant patients' comfort and experience with telemedicine as a substitute for an in-person visit.

We also feel that this survey data can be used by other kidney transplant centers as a tool to help expand their telemedicine programs as a safe and effective way to provide care to their kidney transplant recipients.

The HRSA defines telemedicine as "the use of electronic information and telecommunications technologies to support longdistance clinical healthcare, patient and professional health-related education, public health, and health administration. Technologies include videoconferencing, the internet, store-and-forward imaging, streaming media, and terrestrial and wireless communications" [19]. This type of visit is usually implemented to replace or supplement an inperson visit [8]. The COVID-19 pandemic has prompted many changes in the way healthcare is provided. The 1135 waiver authority and
Coronavirus Preparedness and Response Supplemental Appropriations Act on March 6 [20], worked to ensure that all Americans, especially those who are at higher risk for complications from COVID-19, have access to technologies to minimize their risk of exposure to the virus as well as the potential for community viral spread. Providers and patients had to use audio and video telecommunication technology for realtime communication between the patient at home and the healthcare center. This allowed for providers to use telemedicine and be paid by Medicare. Prior to this, Medicare would only reimburse telemedicine if outpatients were located in a rural area. In 2018, our Transplant Institute established a telemedicine clinic in a rural and underserved county in South Georgia where patients in surrounding areas (including parts of Eastern Alabama) could travel to for their post-kidney transplant clinic visits instead of driving many hours to Atlanta. The 1135 waiver's expansion into telemedicine markedly increased our program's access to post-kidney transplant patients during the COVID-19 pandemic, allowing this cohort to be seen in their homes to minimize their potential viral exposure. This is primarily how we were able to see so many patients through Telemedicine in this short period of time.

Published studies assessing the use of telemedicine in transplantation are limited with no known previous studies evaluating patient satisfaction using this modality instead of an in-person visit. Studies have evaluated cost savings using telemedicine for the prekidney transplant evaluation [21] and post-kidney transplant visits [22]. One group assessed renal transplant recipients' attitudes towards using a smartphone for medication adherence monitoring and found that $79 \%$ had a positive attitude towards using a prototype system if it was free to them [23].

There are currently further attempts to improve other longstanding challenges of Telemedicine. On December 9, 2020, the fourth amendment to the Declaration Under the Public Readiness and Emergency Preparedness Act for Medical Countermeasures Against COVID-19 was released with the intention of allowing providers to see patients across state lines [24]. The purpose of this amendment is to 
"facilitate the public health mitigation strategies during this pandemic by increasing social distancing." This allows great potential for the growth of Telemedicine in transplant for both out of state recipients and live kidney donor evaluations and follow up care. However, given the language above there is uncertainty to how long this amendment will last and individual state laws still supersede this amendment. In essence the rules and regulations governing seeing patients via telemedicine across state lines remains a gray area. Some states have reciprocity while others do not. During the study period, two of our transplant nephrologists had to apply for, and received, an emergency Alabama license to see our recipients who lived in that state. Despite the amendment above a provider with a Georgia license still must have an Alabama license to see a patient in Alabama. However, the provider can actually see a patient who lives in Alabama if the patient drives across the state line into Georgia for their telemedicine visit. Ongoing challenges include the cost of telemedicine infrastructure, insufficient staff and administrative support, patient access to Internet and proper electronic videoconferencing devices, concerns for patient privacy, and patient language barriers. Starting August 2020, our hospital system encouraged us to safely bring more patients back into our clinic to capture a facility fee that the system cannot capture using Telemedicine. In addition, some of our patients were unable to utilize the Telemedicine application due to inadequate $\mathrm{Wi}-\mathrm{Fi}$ in rural areas and their visits were converted to a Telephone visit. This resulted in a lower billing code than a video visit.

Our single-center, retrospective study has limitations. The generalizability of our findings is limited by the fact that all patients in this cohort were from the same transplant center. Those patients more satisfied with their experience may have been more likely to complete the survey. Those that chose to participate in this study may have been more motivated to use telemedicine due to their fear of traveling to a hospital based practice during the COVID-19 pandemic. Thus, we will plan to evaluate more patient experiences through this survey once the pandemic ends to determine if these results are reproducible.

One unexpected finding in our study was that patients age 51-64 were significantly less satisfied with the quality of the Internet connection than those patients less than 50 years old but also those 65 years and older. This may have been due to elderly patients having a support person assisting them with their telemedicine visit. We recommend adding a question about support to future patient satisfaction surveys about telemedicine visits. Further studies evaluating short and longterm patient outcomes, cost effectiveness, and patient satisfaction are needed to help determine the overall potential and effectiveness of telemedicine as an alternative for in-person kidney transplant patient care.

Our study allowed post-kidney transplant patients to have an opportunity to reflect on their telemedicine visit and to offer feedback to our Institute in an effort to improve our Telemedicine program. Telemedicine has been one of the most prominent changes implemented in the care of our post-kidney transplant patients, and our program plans to continue to use this modality even after the pandemic is over. It has proven to be an invaluable part of our patients' follow-up care given their immunosuppressed status in the setting of COVID-19. This study has allowed us to suggest that Telemedicine be used as a viable option for post-kidney transplant care given overall patient satisfaction while retaining excellent outcomes.

\section{Acknowledgements}

We would like to acknowledge Krista Lentine MD, PhD, Professor, Department of Medicine, Division of Nephrology at St. Louis University School of Medicine for reviewing our manuscript.

\section{References}

1. https://www.ncbi.nlm.nih.gov/books/NBK207145/

2. Preston J, Brown FW, Hartley B (1992) Using telemedicine to improve health care in distant areas. Hosp Community Psychiatry 43: 25-32. [Crossref]

3. Wittson CL, Benschoter R (1972) Two-way television: helping the medical center reach out. Am J Psychiatry 129: 624-627. [Crossref]

4. www.healthit.gov

5. WHO (2019) Coronavirus disease situation report. World Health Organization.

6. Siwicki B (2020) Telemedicine during COVID-19: Benefits, limitations, burdens, adaptation. Healthcare IT news.

7. CDC (2020) Using Telehealth to Expand Access to Essential Health Services during the COVID-19 Pandemic.

8. Abuzeineh M, Muzaale AD, Crews DC, Avery RK, Brotman DJ, et al. (2020) Telemedicine in the Care of Kidney Transplant Recipients With Coronavirus Disease 2019: Case Reports. Transplant Proc 52: 2620-2625. [Crossref]

9. Watford, DJ, Cheng, XS, Han, J, Stedman, MR, Chertow, GM, et al. (2020) Toward telemedicine-compatible physical functioning assessments in kidney transplant candidates. Clin Transplant 35: e14173. [Crossref]

10. Beatrice P, Forbes RC (2020) The Role of Telemedicine in Kidney Transplantation Opportunities and Challenges. Kidney360 1: 420-423. [Crossref]

11. Hollander JE, Carr BG (2020) Virtually perfect? Telemedicine for COVID-19. N Eng J Med 382: 1679-1681. [Crossref]

12. Chang J, Diop M, Burgos YL, Blackstock DM, Fernandez HE, et al. (2020) Telehealth in outpatient management of kidney transplant recipients during COVID-19 pandemic in New York. Clin Transplant 34: e14097. [Crossref]

13. Alberici F, Delbarba E, Manenti C, Econimo L, Valerio F, et al. (2020) A single center observational study of the clinical characteristics and short-term outcome of 20 kidney transplant patients admitted for SARS-CoV2 pneumonia. Kidney Int 97: 1083-1088. [Crossref]

14. Akalin E, Azzi Y, Bartash R, Seethamraju H, Parides M, et al. (2020) Covid-19 and Kidney Transplantation. N Engl J Med 382: 2475-2477. [Crossref]

15. Elias M, Pievani D, Randoux C, Louis K, Denis B, et al. (2020) COVID-19 Infection in Kidney Transplant Recipients: Disease Incidence and Clinical Outcomes. JASN 31: 2413-2423.

16. Slightam C, Gregory AJ, Hu J, Jacobs J, Gurmessa T, et al. (2020) Patient Perceptions of Video Visits Using Veteran Affairs Telehealth Tablets: Survey Study. J Med Internet Res 22: e15682. [Crossref]

17. McGrail KM, Ahuja MA, Leaver CA (2017) Virtual Visits and Patient-Centered Care: Results of a Patient Survey and Observational Study. J Med Internet Res 19: e177 [Crossref]

18. Walkden JA, McCullagh PJ, Kernohan WG (2019) Patient and carer survey of remote vital sign telemonitoring for self-management of long-term conditions. BMJ Health Care Inform 26: e100079 [Crossref]

19. https://www.healthlit.gov/providers-professionals/faqs/what-telehealth-howtelehealth-different-telemedicine

20. https://www.cms.gov/newsroom/fact-sheets/medicare-telemedicine-health-careprovider-fact-sheet?inf_contact_key=38ca3f198618fc3aeba4091611f5b055680f89141 73f9191b1c0223e68310bb1

21. Forbes RC, Rybacki DB, Johnson TB, Hannah-Gillis A, Shaffer D, et al. (2018) A Cost Comparison for Telehealth Utilization in the Kidney Transplant Waitlist Evaluation Process. Transplantation 102: 279-283. [Crossref]

22. Kalil R (2013) Improving access to specialized care: the telehealth kidney transplant clinic at the Iowa City VAMC. Veterans Rural Health Resource Center.

23. McGillicuddy JW, Weiland AK, Frenzel RM, Mueller M, Brunner-Jackson BM, et al (2013) Patient attitudes toward mobile phone-based health monitoring: questionnaire study among kidney transplant recipients. J Med Internet Res 15: e6. [Crossref]

24. Federal Register (2020) The daily journal of United States. National Archives 85 79190-79198.

Copyright: (C2021 Wolf J. This is an open-access article distributed under the terms of the Creative Commons Attribution License, which permits unrestricted use, distribution, and reproduction in any medium, provided the original author and source are credited. 